\title{
Assessing soil bacterial community and dynamics by integrated high-throughput absolute abundance quantification
}

\author{
Jun Lou ${ }^{1}$, Li Yang ${ }^{1}$, Haizhen Wang ${ }^{\text {Corresp., }}{ }^{1}$, Laosheng Wu ${ }^{1,2}$, Jianming Xu ${ }^{\text {Corresp. } 1}$ \\ 1 Institute of Soil and Water Resources and Environmental Science, College of Environmental and Resource Sciences, Zhejiang Provincial Key Laboratory \\ of Agricultural Resources and Environment, Zhejiang University, Hangzhou, China \\ 2 Department of Environmental Sciences, University of California, Riverside, Riverside, United States \\ Corresponding Authors: Haizhen Wang, Jianming Xu \\ Email address: wanghz@zju.edu.cn, jmxu@zju.edu.cn
}

Microbial ecological studies have been remarkably promoted by the high-throughput sequencing approach with explosive information of taxonomy and relative abundance. However, relative abundance does not reflect the quantity of the microbial community and the inter-sample differences among taxa. In this study, we refined and applied an integrated high-throughput absolute abundance quantification (iHAAQ) method to better characterize soil quantitative bacterial community through combining the relative abundance (by high-throughput sequencing) and total bacterial quantities (by quantitative PCR). The proposed iHAAQ method was validated by an internal reference strain EDL933 and a laboratory strain WG5. Application of the iHAAQ method to a soil phenanthrene biodegradation study showed that for some bacterial taxa, the changes of relative and absolute abundances were coincident, while for others the changes were opposite. With the addition of a microbial activity inhibitor $\left(\mathrm{NaN}_{3}\right)$, the absolute abundances of soil bacterial taxa, including several dominant genera of Bacillus, Flavobacterium, and Paenibacillus, decreased significantly, but their relative abundances increased after 28 days of incubation. We conclude that the iHAAQ method can offer more comprehensive information to reflect the dynamics of soil bacterial community with both relative and absolute abundances than the relative abundance from high-throughput sequencing alone. 
$1 \quad$ Assessing soil bacterial community and dynamics by integrated

3 Jun Lou ${ }^{1,+}$, Li Yang ${ }^{1,+}$, Haizhen Wang ${ }^{1, *}$, Laosheng $\mathrm{Wu}^{1,2}$ and Jianming $\mathrm{Xu}^{1,{ }^{1,}}$

4

$5{ }^{1}$ Institute of Soil and Water Resources and Environmental Science, College of

6 Environmental and Resource Sciences, Zhejiang Provincial Key Laboratory of

7 Agricultural Resources and Environment, Zhejiang University, Hangzhou, China

$8{ }^{2}$ Department of Environmental Sciences, University of California, Riverside, CA, $9 \quad$ USA

10

$11{ }^{+}$These authors contributed equally to this work.

$12{ }^{*}$ Correspondence:

13 Haizhen Wang and Jianming Xu,

14

15 Email address: wanghz@zju.edu.cn and jmxu@zju.edu.cn.

16 


\section{Manuscript to be reviewed}

\section{ABSTRACT}

18 Microbial ecological studies have been remarkably promoted by the high-throughput

19 sequencing approach with explosive information of taxonomy and relative abundance.

20 However, relative abundance does not reflect the quantity of the microbial community

21 and the inter-sample differences among taxa. In this study, we refined and applied an

22 integrated high-throughput absolute abundance quantification (iHAAQ) method to

23 better characterize soil quantitative bacterial community through combining the

24 relative abundance (by high-throughput sequencing) and total bacterial quantities (by

25 quantitative PCR). The proposed iHAAQ method was validated by an internal

26 reference strain EDL933 and a laboratory strain WG5. Application of the iHAAQ

27 method to a soil phenanthrene biodegradation study showed that for some bacterial

28 taxa, the changes of relative and absolute abundances were coincident, while for

29 others the changes were opposite. With the addition of a microbial activity inhibitor

$30\left(\mathrm{NaN}_{3}\right)$, the absolute abundances of soil bacterial taxa, including several dominant

31 genera of Bacillus, Flavobacterium, and Paenibacillus, decreased significantly, but

32 their relative abundances increased after 28 days of incubation. We conclude that the

33 iHAAQ method can offer more comprehensive information to reflect the dynamics of

34 soil bacterial community with both relative and absolute abundances than the relative

35 abundance from high-throughput sequencing alone. 


\section{Manuscript to be reviewed}

36

37

\section{Introduction}

Bacteria are the essential components of soil ecosystem and play a vital role in the material cycle and energy flow in the Earth ecosystem (Whitman et al. 1998). It was estimated that there are $4-6 \times 10^{30}$ cells of prokaryotes on Earth and $2.6 \times 10^{30}$ in soil, which is the most diverse and abundant cellular life form on Earth (Whitman et al. 1998; Curtis \& Sloan 2005). Soil bacteria have been studied intensively for more than a hundred years from individuals and its communities, but there are still more than $85-99 \%$ of bacteria that cannot be isolated and grown in culture mediums (Lok 2015). Therefore, the question remains how many bacteria are there (absolute and relative abundances) and who are they (kinds of species) in a soil, which consists a community.

Over the past few decades, scientists have attempted to answer these questions. The classical plate-counting method via counting the different colonies on plate was the simplest way to simultaneously obtain the information of absolute and relative abundances of soil bacteria, but the method has the limitation because of the low percentange of cultivable bacteria in soil (Davey 2011; Blagodatskaya \& Kuzyakov 2013). Many other methods have been applied to explore the absolute or relative abundances of soil bacterial community. For example, Brookes et al. (1985) and Vance et al. (1987) tried to estimate the total microbial abundance by measuring the microbial biomass-N (MBN) and $-\mathrm{C}(\mathrm{MBC})$ in soil. With the development of molecular biology and the more verified specific target genes, the quantitative PCR 


\section{Manuscript to be reviewed}

57 (qPCR) also becomes a powerful and accurate technique to measure the total or

58 specific microbial absolute abundance in soil (Philippot et al. 2009).

Various biomarker and molecule methods were also found to be useful for exploring the community sturctures of soil bacteria. These methods include the phospholipid fatty acids (PLFAs), polymerase chain reaction-denaturing gradient gel electrophoresis (PCR-DGGE), clone library, catalysed reporter deposition fluorescence in situ hybridization (CARD-FISH), microfluidic qPCR, etc. (Li et al. 2006; Ding et al. 2011; Cai et al. 2016; Kleyer et al. 2017). Especially, establishment of the high-throughput sequencing method opened a new era for microbiology. Confirmed by the microbial mock community and multiple studies, this method can reveal the relative abundance as well as kinds of species of soil bacterial community with unprecedented amount of information (Wang et al. 2007; Caporaso et al. 2012; Cai et al. 2016; Singer et al. 2016; Tourlousse et al. 2017).

Since the high-throughput sequencing technique can acquire rich information of

71 relative abundance (Caporaso et al. 2012; Kozich et al. 2013; Dannemiller et al. 2014;

72 Prest et al. 2014; Stokell et al. 2016; Props et al. 2017; Zhang et al. 2017), it was

73 combined with the absolute quantification methods of total microorganism to

74 characterize the more informative changes of microbial communities in several 75 studies (Dannemiller et al. 2014; Prest et al. 2014; Props et al. 2017; Zhang et al. 76 2017). In the combined methods, the flow cytometric (FCM), adenosine triphosphate 77 (ATP), heterotrophic plate count (HPC), qPCR, PLFAs, and MBC, were used to 


\section{Manuscript to be reviewed}

78 quantify the absolute abundance of total microorganism. For example, Prest et al.

79 (2014) combined the FCM and 16S rRNA gene pyrosequencing and successfully

80 revealed the change of bacterial community in drinking water, which was

81 undetectable by the ATP and HPC measurements. Dannemiller et al. (2014)

82 quantitatively compared the fungal aerosol populations by combining the qPCR and

83 high-throughput sequencing methods, which were verified by the four selected

84 specific taxa, Alternaria alternata, Cladosporium cladosporioides, Epicoccum nigrum,

85 and Penicillium/Aspergillus spp.

86 Recently, Zhang et al. (2017) investigated soil bacterial communities at two

87 different locations by coupling the results of ATP, qPCR, PLFAs, and the relative

88 abundances of high-throughput sequencing technique. Nevertheless, the methods were

89 not verified using specific strains or internal strains as it was done in the previous

90 study by Dannemiller et al. (2014). So far, no research has proved the feasibility of

91 combining the absolute quantification methods of total microorganism and

92 high-throughput sequencing data to characterize soil bacterial communities, which is

93 much more complex than in other environments (Whitman et al. 1998; Smets et al.

94 2016; Tourlousse et al. 2017). As mentioned above, the qPCR method is an accurate

95 method for the absolute abundance of genes, while the high-throughput sequencing is

96 the primary method for the relative abundance of bacteria community. Therefore, we

97 proposed an integrated high-throughput absolute abundance quantification (iHAAQ) 


\section{Manuscript to be reviewed}

98 method for soil quantitative bacterial ecology through combining the qPCR and

99 high-throughput sequencing techniques in this study.

100 Meanwhile, the accuracy of the iHAAQ method was tested by an internal

101 reference strain, Escherichia coli O157:H7 strain EDL933, which can be easily

102 classified and distinguished from soil indigenous bacteria. Also, the internal reference

103 strain can be absolutely quantified by the qPCR method because it contains the

104 flagellar biosynthesis protein FliC gene (fliC) (Latif et al. 2014). Furthermore, the

105 iHAAQ method was applied to characterize the bacterial community changes in soil

106 phenanthrene biodegradation.

107

108 Materials and methods

109 Bacteria strains, culture medium and chemicals

110 The Escherichia coli O157:H7 strain EDL933 (ATCC 43895), SMAC (Sorbitol

111 MacConkey)-BCIG (5-bromo-4-chloro-3-indoxyl- $\beta$-D-glucuronide) agar (LabM,

112 Lancashire, UK) and Luria-Bertani (LB) medium (Becton, Dickinson and Company,

113 Spark, USA) used herein were described previously (Wang et al. 2014). After

114 incubating at $37^{\circ} \mathrm{C}$ on a water orbital shaker (250 rpm), the cultured strain EDL933

115 was harvested by centrifugation at $4{ }^{\circ} \mathrm{C}(6,000 \times \mathrm{g}$ for $10 \mathrm{~min})$ and washed three times

116 with sterile deionized water (Wang et al. 2014). The cell pellets were re-suspended in

117 sterile deionized water to achieve the cell concentration of near $2.1 \times 10^{11} \mathrm{CFU} \mathrm{mL}^{-1}$

118 (CFU, colony-forming units). Diluted with sterile deionized water, the gradient 


\section{Manuscript to be reviewed}

119 concentrations of strain EDL933 in the order of $2.1 \times 10^{11}$ to $2.1 \times 10^{6} \mathrm{CFU} \mathrm{mL}^{-1}$

120 were prepared and added to soil samples.

121 The Massilia sp. strain WG5 (CCTCC AB 2015362) was isolated from a PAHs

122 contaminated soil from Jiangsu Province, China, which has a high

123 phenanthrene-degrading ability (Lou et al. 2016; Wang et al. 2016). After pre-cultured

124 in LB medium, the strain WG5 was harvested by centrifugation at $4{ }^{\circ} \mathrm{C}(6,000 \times \mathrm{g}$ for

$12510 \mathrm{~min}$ ) and washed three times with sterile deionized water. The cell pellets were

126 then re-suspended to $\mathrm{D}_{600 \mathrm{~nm}} 1.0$ (approximately $1.5 \times 10^{8} \mathrm{CFU} \mathrm{mL}^{-1}$ ) for later use.

127 Phenanthrene (PHE; Sigma-Aldrich, Shanghai, China), rifampicin (Fisher

128 Scientific, Fair Lawn, USA), nalidixic acid (Sigma-Aldrich, Saint Louis, USA) and

129 other inorganic chemicals used in this study were of the HPLC or analytical grade.

130 The extraction and detection of PHE in soil were followed by the method of Gu et al.

131 (2017).

132 Experiment set-up and DNA extractions

133 The soil was collected from the surface horizon $(0-20 \mathrm{~cm})$ near a steel mill in Fujian

134 Province, China. Three composite soil samples were taken to the laboratory using

135 coolers with ice bags. Then, the soil was sieved $(2 \mathrm{~mm})$ and stored at $4{ }^{\circ} \mathrm{C}$ for use.

136 The soil chemical and physical properties are the same as reported by $\mathrm{Gu}$ et al.

137 (2017).

138 The experiment included 10 treatments: control (Treatment Cont, soil only), soil

139 added with strain EDL933 at 6 concentrations (near $10^{9}, 10^{8}, 10^{7}, 10^{6}, 10^{5}$, and $10^{4}$ 


\section{Manuscript to be reviewed}

$140 \mathrm{CFU}$ (g dry wt soil) ${ }^{-1}$, corresponding to Treatments E9, E8, E7, E6, E5 and E4), soil

141 added with PHE (100 $\mu \mathrm{g}$ (g dry wt soil $)^{-1}$, Treatment $\left.\mathrm{P}\right)$, soil added with PHE $(100 \mu \mathrm{g}$

142 (g dry wt soil) $^{-1}$ ) and strain WG5 (approximately $1.00 \times 10^{7}$ CFU (g dry wt soil) ${ }^{-1}$,

143 Treatment W), and soil added with PHE (100 $\mu \mathrm{g}$ (g dry wt soil) $\left.{ }^{-1}\right)$ and sodium azide

$144\left(\mathrm{NaN}_{3}, 0.1 \%\right.$, w/w, Treatment $\left.\mathrm{S}\right)$. The purpose of adding $\mathrm{NaN}_{3}$ was to inhibit the

145 native microbial activity (Wei \& Pan 2010).

146 In Treatments E9, E8, E7, E6, E5 and E4, 1.0-mL aliquot of strain EDL933 with

147 the gradient concentrations in the order of $2.1 \times 10^{11}$ to $2.1 \times 10^{6} \mathrm{CFU} \mathrm{mL}^{-1}$,

148 respectively, was added to each soil sample (30 g frozen-dry basis). Treatments E9,

149 E8, E7, E6, E5, E4, and Cont were used to develop the iHAAQ method, and

150 Treatments $\mathrm{P}, \mathrm{W}$, and $\mathrm{S}$ were used to reveal soil bacterial community dynamics

151 during PHE biodegradation.

152 Samples of each treatment were prepared in triplicate by putting $30 \mathrm{~g}$ (frozen-dry

153 basis) of soil into a $100-\mathrm{mL}$ flask. All the treated soils were thoroughly mixed (two

154 hours) and soil moisture was adjusted to $100 \%$ of the field capacity (soil water content

155 at $-33 \mathrm{kPa}$ ) by adding sterile deionized water. Ten grams (frozen-dry basis) of soil

156 were sampled immediately from each flask. In addition, all flasks of Treatments $\mathrm{P}, \mathrm{W}$,

157 and $\mathrm{S}$ were incubated in the dark at $28 \pm 1{ }^{\circ} \mathrm{C}$ and aerated weekly on the Clean Bench

158 for $30 \mathrm{~min}$. Sterile deionized water was added to compensate the soil moisture loss

159 during incubation and to maintain quasi-constant soil moisture content for the samples. 


\section{Manuscript to be reviewed}

160 After 28 days of incubation, ten grams (frozen-dry basis) of soil were sampled from

161 each flask of Treatments $\mathrm{P}, \mathrm{W}$, and $\mathrm{S}$ for DNA extraction.

162 All the soil samples collected from the flasks were immediately frozen and stored

163 in a freezer $\left(-80^{\circ} \mathrm{C}\right)$. Aliquot sample of $0.21 \mathrm{~g}$ (frozen-dry basis) per collected sample

164 was used for DNA extraction using the MoBio PowerSoil DNA Isolation kit (MoBio

165 Laboratories, Carlsbad, CA, USA). The extracted DNA was stored in the same freezer

$166\left(-80^{\circ} \mathrm{C}\right)$ before $\mathrm{qPCR}$ analysis.

167 Quantitative PCR analyses

168 The qPCR analyses were performed to quantify the specific genes of the extracted

169 DNA with three replicates using a StepOnePlus ${ }^{\mathrm{TM}}$ Real-Time PCR System instrument

170 (Applied Biosystems, Foster City, CA, USA). The two pairs of primers, 341F (5'-

171 CCTACGGGAGGCAGCAG -3') and 534R (5'- ATtACCGCGGCTGCTGG -3'),

$172 \quad 520 \mathrm{~F} \quad\left(5^{\prime}-\quad\right.$ AYTGGGYDTAAAGNG $\left.\quad 3^{\prime}\right)$ and 802R (5'-

173 TACNVGGGTATCTAATCC -3'), were chosen to detect the copy numbers of $16 \mathrm{~S}$

174 rRNA gene of total bacteria in V3 and V4 variable regions, respectively (Reddy et al.

175 2012; Guinane et al. 2013). To measure the abundance of strain EDL933, the fliC

176 gene was selected from its chromosome, which had only one copy in the genome

177 (Latif et al. 2014). The forward and reverse primers used were 5'-

178 GCGAAGTTAAACACCACGAC -3' and 5'- ACCCGTACCAGCAGTAGATT -3',

179 respectively (Jun et al. 2011). 

(cycle threshold) method. All qPCR reactions were conducted in triplicate.

\section{High-throughput sequencing and data processing}

192 According to the method reported by (Ma et al. 2016), each composite DNA sample

193 for sequencing was mixed by combining equal amounts of DNA extraction of the

194 three replicates. The bacterial communities of the Cont, E9 to E4, P, W, and S

195 treatments were amplified with the V4 region of primers $(520 \mathrm{~F}, 5$ '-

196 AYTGGGYDTAAAGNG -3' and 802R, 5'- TACNVGGGTATCTAATCC -3'), and

197 then sequenced with Illumina Miseq platform following standard protocols. The

198 quality control of raw sequencing reads was performed using QIIME software

199 (version 1.7.0) (Caporaso et al. 2010). The sequences were removed if the average 200 quality in a moving 5 bps window lower than Q20, length less than 150 bps and 


\section{Manuscript to be reviewed}

201 having the ambiguous barcode. The paired-end sequences were spliced by the same

202 index with overlap no less than $10 \mathrm{bps}$ and no mismatch using FLASH (Magoc \& 203 Salzberg 2011). The chimera sequences were de novo identified and removed using 204 UCHIME (Edgar et al. 2011).

205 After quality filtering, the sequences clustering was performed using UCLUST 206 with a 97\% similarity and sorted out as operational taxonomic units (OTUs) (Edgar 207 2010). Then, the OTUs were classified using RDP-classifier to match to SILVA 208 database release 119 (Wang et al. 2007; Quast et al. 2013). The raw data obtained in 209 this research were deposited to NCBI SRA (Sequence Read Archive; 210 http://www.ncbi.nlm.nih.gov/sra/) under accession numbers SRP097773 and 211 SRP105351.

212 Absolute quantification of soil bacteria and its community by the iHAAQ 213 method

214 The absolute abundance of each phylum or genus in the soil bacterial community was 215 calculated by multiplying total bacterial quantities (the copy number of 16S rRNA 216 gene of total bacteria from qPCR) and the corresponding relative abundance from 217 high-throughput sequencing (Fig. 1). The calculated absolute abundances of 218 Escherichia-Shigella, Esch-V3 and Esch-V4, were based on its relative abundance 219 and the total bacterial quantities measured by V3 and V4 regions of 16S rRNA gene, 220 respectively. Since the $16 \mathrm{~S}$ rRNA gene varied in copy numbers among the different 221 bacteria genomes (Latif et al. 2014; Sun et al. 2013), 7 copies of 16S rRNA gene and 
2221 copy of $f l i C$ gene in one genome of strain EDL993 (NZ_CP008957, NCBI:

223 http://www.ncbi.nlm.nih.gov) were considered in this study. The absolute abundances 224 of Escherichia-Shigella (Esch-V3 and Esch-V4) and $7 \times f l i C$ gene copies were 225 logarithmically transformed before performing linear regression analysis.

226 Linear regression was performed using Origin 2016 (OriginLab, Northampton, 227 USA), and analysis of variance (ANOVA) used with SPSS 20 (IBM, Armonk, USA). 228 The homogeneity of variances was tested by Levene's test before ANOVA. Tukey's 229 honestly significant difference test was used when the variances were homogeneous. 230 Otherwise Tamhane's T2 test was used. Heatmaps and cluster analyses were 231 performed using $\mathrm{R}$ software version 3.3.1 with pheatmap package (RCore 2013; 232 Kolde 2015).

\section{Results}

\section{Total bacterial quantity and strain EDL933 measurement by qPCR}

235 The background total bacterial quantities (the copy numbers of 16S rRNA gene) were $2363.53 \times 10^{9} \pm 1.23 \times 10^{8}$ and $5.82 \times 10^{9} \pm 3.29 \times 10^{8}$ copies $(\mathrm{g} \text { dry wt soil })^{-1}$, 237 respectively, for V3 and V4 regions. The total bacterial quantities in Treatments from 238 E9 to E4 ranged from $7.00 \times 10^{10}$ to $3.53 \times 10^{9}$ and from $7.23 \times 10^{10}$ to $5.82 \times 10^{9}$ 239 copies (g dry wt soil) $)^{-1}$ for V3 and V4 regions, respectively. The total bacterial 240 quantities of V3 and V4 regions in Treatments E9 and E8 were significantly $(p<0.05)$

241 higher than those in other treatments (Fig. S1, Supporting Information). Compared 242 with the background total bacterial quantity $\left.\left(\sim 10^{9} \text { copies (g dry wt soil }\right)^{-1}\right)$, the added 


\section{Manuscript to be reviewed}

243 strain EDL933 in the order of $10^{4}$ to $10^{7}$ copies (g dry wt soil) ${ }^{-1}$ (Table 1) only had a

244 slight influence on the total bacterial quantities in Treatments E4 to E7 (Fig. S1, 245 Supporting Information).

246 A standard curve of the $f l i C$ gene in the range of $3.60 \times 10^{1}$ to $3.60 \times 10^{9}$ copies

$247 \mu \mathrm{L}^{-1}$ was constructed for qPCR. The $\mathrm{C}_{\mathrm{t}}$ value of the standard sample containing $3.60 \times$

$24810^{1}$ copies $\mu \mathrm{L}^{-1}$ was $32.62 \pm 0.76$, and its standard deviation (SD) was greater than 0.5 .

249 However, the $C_{t}$ value of Cont $(33.05 \pm 0.98)$ was even greater than the $C_{t}$ value of

250 the standard sample containing $3.60 \times 10^{1}$ copies $\mu \mathrm{L}^{-1}$. This $\mathrm{qPCR}$ result indicated 251 that the detected gene in the control soil was not the fliC gene (Fig. S2, Supporting 252 Information).

In Treatments from E9 to E4, the $C_{t}$ values (from $13.73 \pm 0.05$ to $29.66 \pm 0.06$ ) of

254 the $f l i C$ gene were all within the range of the standard curve, and all SD values were

255 lower than 0.5. The fliC gene copies and added concentrations of strain EDL933 (data

256 converted into $\left.\log _{10}\right)$ fitted well to a linear model $\left(R^{2}=0.999\right)$ (Fig. S3, Supporting

257 Information). With or without intercept, the slopes were close to 1, indicating that the 258 quantified $f l i C$ gene in the extracted soil DNA can be used to predict the 259 concentrations of strain EDL993 in soil with high accuracy.

260 Establishment and validation of the iHAAQ method

261 After quality filtering, there was a total of 465,220 high-quality sequences (66460 262 sequences per sample), and the sequences were classified into 35 phyla. At the genus 263 level, strain EDL933 was identified and classified as genus Escherichia-Shigella in 


\section{Manuscript to be reviewed}

264 the SILVA database. The relative abundances of genus Escherichia-Shigella in

265 Treatments from E4 to E9 were much higher than that in Cont, and they increased

266 when more strain EDL933 was added to the soil (Fig. 2). The percentage of genus

267 Escherichia-Shigella in phylum Proteobacteria was $89.76 \%$ in Treatment E9,

268 compared with $0.07 \%$ in Cont.

269 After the $f l i C$ gene copies were multiplied by 7 times (marked as $7 \times f l i C$ ), they

270 were in the same order of magnitude of the absolute abundance of Esch-V3 and

271 Esch-V4, except for Treatment E4 (Table 1). The ANOVA results showed that there

272 was no significant difference $(p>0.05)$ between the $7 \times f l i C$ and Esch-V4 in all the

273 treatments, except for Treatment E4 (Table 1). In Treatment E4, both the fliC gene

274 copy number and $7 \times f l i C$ gene copy number were significant lower than the absolute

275 abundances of Esch-V3 and Esch-V4.

276 Furthermore, the $7 \times f l i C$ gene copies were linearly related to the calculated

277 absolute copies of Esch-V3 and Esch-V4 (Table 1, Fig. 3). All the four linear

278 equations fitted to the experimental data very well $\left(\mathrm{R}^{2}, 0.998-0.999\right)$, indicating that

279 the $7 \times$ fliC gene copies of the strain EDL933 can be reliably predicted from the

280 absolute abundances of Esch-V3 and Esch-V4 (Fig. 3). Thus, it is apparent that the

281 iHAAQ method based on the integration of qPCR and high-throughput sequencing

282 can be used to calculate the absolute abundance (Fig. 1, Fig. 4).

283 Examining dynamics of soil bacterial communities by the iHAAQ method. 


\section{Manuscript to be reviewed}

284 From 7 days to 28 days incubation, the residual PHE was declined rapidly from 22.01

285 to $8.44 \mu \mathrm{g}$ (g dry wt soil) $)^{-1}$ in Treatment $\mathrm{P}$ and from 7.53 to $4.38 \mu \mathrm{g}$ (g dry wt soil $)^{-1}$ in

286 Treatment W. Compared with Treatments P and W, Treatment S contained the highest

287 residual PHE and had the slightest change during the 28-d incubation (47.79 - 60.45

$\left.288 \mu \mathrm{g}(\mathrm{g} \text { dry wt soil })^{-1}\right)$. Following the procedures as shown in Fig. 1, the dynamics of

289 soil bacterial community in Treatments $\mathrm{P}, \mathrm{W}$, and $\mathrm{S}$ were assessed by the iHAAQ

290 method. The total bacterial quantities increased with the incubation time in

291 Treatments $\mathrm{P}$ and $\mathrm{W}$, but decreased with the incubation time in Treatment S (Fig. S4,

292 Supporting Information).

293 There were mainly 17 phyla in which the relative abundances were greater than

$2940.1 \%$ in each of the samples (Table S1, Fig. S5, Supporting Information). The

295 dynamics of relative abundances reflected the soil bacterial composition changes

296 during incubation (Fig. S5, Supporting Information). Overall, the relative abundances

297 decreased with the increase of incubation time in more than half of the phyla. The

298 phyla of Firmicutes, Proteobacteria, Planctomycetes, Bacteroidetes, and

299 Actinobacteria decreased by $5.58 \%, 1.93 \%, 1.59 \%, 1.28 \%$, and $1.24 \%$, respectively,

300 in Treatment P; the phyla of Proteobacteria, Firmicutes, and Verrucomicrobia

301 decreased by $9.24 \%, 3.41 \%$, and $0.93 \%$, respectively, in Treatments $\mathrm{W}$; and the phyla

302 of Actinobacteria, Chloroflexi, Gemmatimonadetes, and Proteobacteria decreased by

$3036.57 \%, 4.24 \%, 2.77 \%$, and $1.40 \%$, respectively, in Treatment S. However, the phylum 


\section{Manuscript to be reviewed}

304 Firmicutes in Treatment $\mathrm{S}$ increased substantially from $8.53 \%$ to $25.87 \%$, and

305 eventually it became the dominated bacteria in soil.

306 Nevertheless, relative abundance does not provide information about change of

307 total bacterial quantities in soil. Based on the absolute abundances calculated by our

308 proposed iHAAQ method, there were only 5 phyla showing decrease in both the

309 relative and absolute abundances in Treatment $\mathrm{P}$, while the relative and absolute

310 abundances of other phyla showed opposite trend (Fig. 1, Fig. 5, Fig. 6, Fig. 7; Table

311 S1, Fig. S5, Supporting Information). As an example, the difference in relative and

312 absolute abundances was especially evident for phylum Proteobacteria in Treatment

$313 \mathrm{P}$, in which the relative abundance decreased by $6.67 \%$, while the absolute

314 abundances increased by $42.22 \%$ and $21.02 \%$ in V3 and V4 regions, respectively.

315 Such inconsistent result was also observed in Treatments W and S. In Treatment W,

316 the relative abundance of 4 and 6 phyla decreased, while the absolute abundances of

317 all phyla increased. In Treatment S, none of the absolute abundances of phylum

318 increased, but the relative abundance of phylum Firmicutes increased by $17.54 \%$.

319 Discrepancy between relative and absolute abundances also occurred at the genus

320 level (Fig. 7, Table S1, Supporting Information). In Treatment P, 135 and 57 opposite

321 results in relative and absolute abundances were observed in V3 and V4 regions,

322 respectively. While in Treatment $\mathrm{W}, 77$ and 160 opposite relative and absolute

323 abundances were found in V3 and V4 regions, respectively. Even more discrepancies

324 (258 and 245 genera in V3 and V4 regions, respectively) were observed in Treatment 


\section{Manuscript to be reviewed}

325 S. While it was a general trend that the relative abundances of genera decreased while

326 their absolute abundances increased in Treatments P and W (Table S1, Supporting

327 Information). The opposite trend was observed in Treatment S, in which the relative

328 abundance increased while the absolute abundance decreased. For instance, the

329 relative abundance of the dominant genus Bacillus, which belonged to the phylum

330 Firmicutes, increased from $3.67 \%$ to $13.11 \%$ in Treatment S (Fig. 7). However, its

331 absolute abundance decreased by more than $20 \%$ (from $8.88 \times 10^{7}$ to $5.26 \times 10^{7}$

332 copies (g dry wt soil) $)^{-1}$ in V3 region, and from $1.10 \times 10^{8}$ to $8.69 \times 10^{7}$ copies $(\mathrm{g}$ dry

333 wt soil) ${ }^{-1}$ in V4 region).

334 The added strain WG5 in the W0 sample was also detected by high-throughput

335 sequencing and classified as genus Massilia. The relative abundance of Massilia was

336 higher than those in the P0 and S0 samples $(<0.10 \%)$. The change in relative and

337 absolute abundances of Massilia were also different in Treatment W after the soil was

338 incubated at $28{ }^{\circ} \mathrm{C}$ for 28 days. Its relative abundances in the samples were $10.71 \%$

339 and 2.71\%, respectively, in Day 0 (W0) and Day 28 (W28) (Fig. 7), dropped almost

340 three quarters $(74.70 \%)$. Whereas its absolute abundances in W0 and W28 samples

341 decreased from $3.86 \times 10^{8}$ to $1.40 \times 10^{8}$ copies (g dry wt soil) $)^{-1}$, and from $5.13 \times 10^{8}$

342 to $2.47 \times 10^{8}$ copies ( $\mathrm{g}$ dry wt soil) $)^{-1}$, representing less than two thirds $(63.69 \%)$ and

343 one half (51.84\%) of decrease, respectively, in V3 and V4 regions.

344 Cluster analysis also showed the discrepancy between the relative and absolute 345 abundances of bacteria in the treatments (Fig. 6, Fig. S6, Supporting Information). 


\section{Manuscript to be reviewed}

346 Based on the relative abundances, the samples of P0, W0 and P28, S0 were clustered

347 into two close groups, respectively, while the samples of W28 and S28 were far away 348 from those groups (Fig. 6A). However, the cluster based on the absolute abundances 349 showed totally different results. The samples of P28, W28 in V3 and V4 regions were 350 clustered into the same group (Fig. 6B, Fig. S6, Supporting Information). Meanwhile, 351 the samples of $\mathrm{P} 0, \mathrm{~W} 0$ and $\mathrm{S} 0, \mathrm{~S} 28$ in V4 region were clustered into two different 352 groups (Fig. 6B), which is more rational than the result in V3 region (Fig. S6, 353 Supporting Information).

\section{Discussion}

355 The V3 and V4 regions of 16S rRNA gene were universally used to detect the total 356 bacterial quantity in soil via qPCR (Reddy et al. 2012; Guinane et al. 2013). Youssef 357 et al. (2009) observed that there exists difference in soil bacterial community in V3 358 and V4 regions. Except for Treatment E9, all other treatments or samples showed that 359 the total bacteria quantities in V4 region were significantly higher than those in V3 360 region. Comparing with the nearly complete $16 \mathrm{~S}$ rRNA gene, the results of V3 region 361 generally underestimated the total quantity of soil bacterial community, while the 362 results of V4 region were usually comparable to it (Youssef et al. 2009). Meanwhile, 363 Wang et al. (2007) also reported that V4 region has the highest reliability in 364 classification among the $16 \mathrm{~S}$ rRNA variable regions. Thus, it was suggested that V4 365 region was the best choice of $16 \mathrm{~S}$ rRNA gene variable regions for bacterial 366 community characterization. Cluster analysis also proved that the results from the 


\section{Manuscript to be reviewed}

367 same region (V4) of qPCR and high-throughput sequencing were better than those

368 from the different regions of them. Therefore, in the following discussion, we focused

369 our discussion only on the results of $16 \mathrm{~S}$ rRNA gene in V4 region.

370 Comparing with the selected taxa reported by Dannemiller et al. (2014), it is very

371 difficult to select a strain from soil to verify the iHAAQ method. As the previous

372 research reported, the fliC gene of strain EDL933 can be precisely measured by qPCR

373 (Jun et al. 2011; Li \& Chen 2012). Therefore, to test the accuracy of absolute

374 abundance calculated by our method, an internal reference strain EDL933 was

375 selected and introduced into the soil for validation. The high $\mathrm{R}^{2}$ values of the linear

376 relationships indicate strong association between the $f l i C$ gene and the actual added

377 strain. The similar result was also found by Tourlousse et al. (2017) that the slopes of

378 the spike-in read counts and input amounts were close to 1 . Thus, we concluded the

379 iHAAQ method based on qPCR and high-throughput sequencing in the same V4

380 region can be used to reliably predict the absolute abundance of Escherichia-Shigella.

381 The validation of the iHAAQ method was further verified by the added Massilia

382 sp. strain WG5 in W0 sample. The absolute abundance of genus Massilia calculated

383 by the iHAAQ method $\left(5.13 \times 10^{8}\right.$ copies $\left.(\mathrm{g} \text { dry wt soil })^{-1}\right)$ was one order of

384 magnitude higher than the added strain WG5 concentration $\left(1.00 \times 10^{7} \mathrm{CFU}(\mathrm{g}\right.$ dry wt

385 soil $^{-1}$ ). After considering that one chromosome of strain WG5 has 9 copies of $16 \mathrm{~S}$

386 rRNA gene (Lou et al. 2016), the calculated absolute abundance of Massilia was close

387 to the added concentration of strain WG5. 


\section{Manuscript to be reviewed}

388 When the iHAAQ method is applied to quantify soil bacterial community

389 dynamics, both similar and opposite trends of relative and absolute abundances were

390 observed, which agreed with early investigations (Dannemiller et al. 2014; Prest et al.

391 2014; Smets et al. 2016; Stokell et al. 2016; Zhang et al. 2017). We observed that both

392 the relative and absolute abundances of genus Massilia decreased in Treatments W

393 after 28 days of incubation. The low residual PHE and its slow decrease in Treatment

394 W indicated its low bioavailability, which might lead to the slight decrease of the 395 genus Massilia.

396 In Treatment $\mathrm{S}$, the addition of $\mathrm{NaN}_{3}$ significantly decreased the absolute 397 abundances of soil bacterial taxa, which agreed with the report of Rouwane et al. 398 (2016). The genus Bacillus became the dominant composition with the increased 399 relative abundance but the decreased absolute abundance in the bacteria community 400 of Treatment S. Klein et al. (1994) stated that some species in genus Bacillus were 401 strongly resistant to $\mathrm{NaN}_{3}$. It might result in the less decrease of genus Bacillus than 402 other bacteria in Treatment S.

403 The relative abundance can reflect the composition changes of the microbial 404 communities, while the absolute abundance can uncover the dynamics of the total 405 quantities (Reddy et al. 2012; Guinane et al. 2013; Dannemiller et al. 2014; Prest et al. 406 2014; Props et al. 2017; Zhang et al. 2017). The relative abundance from 407 high-throughput sequencing can only partially characterized the bacterial community 408 (Smets et al. 2016; Props et al. 2017; Tourlousse et al. 2017). The actual microbial 
409 community dynamics can be more objectively described by both the relative and

410 absolute abundances from the iHAAQ method than by the relative abundance alone.

411 Furthermore, even if the relative abundance of samples had been obtained from

412 the high-throughput sequencing, the absolute abundance of each taxon in the samples

413 will be achieved with the supplementary qPCR analysis. It was recommended to use

414 the same variable region of 16S rRNA gene for qPCR and high-throughput

415 sequencing. Hence, the iHAAQ method is suitable to determine the absolute

416 abundance of bacterial community and can be applied to studying the quantitative

417 bacterial ecology in soil.

418 It is worthy to mention that the range of the valid absolute abundance of each

419 taxon is limited by the high-throughput sequencing technique. Based on

420 pyrosequencing data of a fungal aerosol population, the exact measure of absolute

421 abundance of the fungal species can be achieved at the sufficiently high relative

422 abundance (above $4.4 \times 10^{-4}$ ) (Dannemiller et al. 2014). In our study, the least

423 sequence number of indigenous bacteria in soil were 5 reads (i.e. the least relative

424 abundance was about $8.0 \times 10^{-5}$ ). The $\mathrm{qPCR}$ results showed that the total bacteria

425 quantities in our samples were from $10^{8}$ to $10^{10}$ copies (g dry wt soil) $)^{-1}$. Therefore, the

426 indigenous bacteria in the soil samples can be detected by the iHAAQ method when

427 their absolute abundances were above $10^{3}$ copies (g dry wt soil) ${ }^{-1}$. With the increase

428 of high-throughput sequencing depth, more rare species with lower abundance can be 
429 detected (Agogue et al. 2011; Polka et al. 2015), which may help to better

430 characterize microbial communities.

\section{Conclusion}

432 Our results indicate that the proposed iHAAQ method allows to obtain the absolute

433 abundance of each taxon in soil bacteria communities by combining qPCR (total

434 bacterial quantity) and high-throughput sequencing (relative abundance of each taxon),

435 which could not be achieved separately by either method. The absolute abundance

436 reflects the dynamics of a bacterial community more accurately than the relative

437 abundance data. In our study, the iHAAQ method was successfully applied to

438 characterize the soil bacterial communities with both relative and absolute abundances,

439 which could provide more information than with the relative abundance alone by

440 high-throughput sequencing. The proposed iHAAQ method could help to study soil

441 quantitative bacterial ecology in future application. 


\section{Manuscript to be reviewed}

\section{REFERENCES}

443 Agogue H, Lamy D, Neal PR, Sogin ML, and Herndl GJ. 2011. Water mass-specificity of 444 bacterial communities in the North Atlantic revealed by massively parallel sequencing. Mol Ecol 20:258-274. 10.1111/j.1365-294X.2010.04932.x

446 Blagodatskaya E, and Kuzyakov Y. 2013. Active microorganisms in soil: Critical review of estimation criteria and approaches. Soil Biol Biochem 67:192-211. 10.1016/j.soilbio.2013.08.024

Brookes PC, Landman A, Pruden G, and Jenkinson DS. 1985. Chloroform fumigation and the release of soil nitrogen: a rapid direct extraction method to measure microbial biomass nitrogen in soil. Soil Biol Biochem 17:837-842.

Cai Y, Zheng Y, Bodelier PL, Conrad R, and Jia Z. 2016. Conventional methanotrophs are responsible for atmospheric methane oxidation in paddy soils. Nat Commun 7:11728. $10.1038 /$ ncomms 11728

Caporaso JG, Kuczynski J, Stombaugh J, Bittinger K, Bushman FD, Costello EK, Fierer N, Pena AG, Goodrich JK, Gordon JI, Huttley GA, Kelley ST, Knights D, Koenig JE, $10.1016 / 0038-0717(85) 90144-0$ 


\section{Manuscript to be reviewed}

462 Caporaso JG, Lauber CL, Walters WA, Berg-Lyons D, Huntley J, Fierer N, Owens SM,

463 Betley J, Fraser L, Bauer M, Gormley N, Gilbert JA, Smith G, and Knight R. 2012.

464 Ultra-high-throughput microbial community analysis on the Illumina HiSeq and 465 MiSeq platforms. ISME J 6:1621-1624. 10.1038/ismej.2012.8

466 Curtis TP, and Sloan WT. 2005. Microbiology. Exploring microbial diversity--a vast below. Science 309:1331-1333. 10.1126/science.1118176

468 Dannemiller KC, Lang-Yona N, Yamamoto N, Rudich Y, and Peccia J. 2014. Combining real-time PCR and next-generation DNA sequencing to provide quantitative comparisons of fungal aerosol populations. Atmospheric Environment 84:113-121. 10.1016/j.atmosenv.2013.11.036

Davey HM. 2011. Life, death, and in-between: meanings and methods in microbiology. Appl Environ Microbiol 77:5571-5576. 10.1128/aem.00744-11

Ding N, Hayat T, Wang J, Wang H, Liu X, and Xu J. 2011. Responses of microbial Soils Sediments 11:1355-1362. 10.1007/s11368-011-0412-x

477 Edgar RC. 2010. Search and clustering orders of magnitude faster than BLAST. Bioinformatics 26:2460-2461. 10.1093/bioinformatics/btq461

479 Edgar RC, Haas BJ, Clemente JC, Quince C, and Knight R. 2011. UCHIME improves sensitivity and speed of chimera detection. Bioinformatics 27:2194-2200. 10.1093/bioinformatics/btr381 


\section{Manuscript to be reviewed}

482 Gu H, Chen Y, Liu X, Wang H, Shen-Tu J, Wu L, Zeng L, and Xu J. 2017. The effective

483

484

485

486

490

491

492

493

494

495

496

497

498

499

500

501 migration of Massilia sp. WF1 by Phanerochaete chrysosporium and its phenanthrene biodegradation in soil. Science of the Total Environment 593-594:695-703. 10.1016/j.scitotenv.2017.03.205

Guinane CM, Tadrous A, Fouhy F, Ryan CA, Dempsey EM, Murphy B, Andrews E, Cotter PD, Stanton C, and Ross RP. 2013. Microbial composition of human appendices from patients following appendectomy. MBio 4:e00366-00312.

Jun L, Xie Y, Xuan X, Chen Z, Yang W, Chun-Xia M, Shuai H, Peng H, Li-Gan X, and Xie Y. 2011. Establishment of real-time quantitative PCR for detection of Escherichia coli O157:H7. Animal Husbandry \& Veterinary Medicine 43:5-9.

Klein M, Hofmann B, Klose M, and Freudl R. 1994. Isolation and characterization of a Bacillus subtilis secA mutant allele conferring resistance to sodium azide. FEMS Microbiol Lett 124:393-397.

Kleyer H, Tecon R, and Or D. 2017. Resolving Species Level Changes in a Representative Soil Bacterial Community Using Microfluidic Quantitative PCR. Front Microbiol 8:2017. 10.3389/fmicb.2017.02017

Kolde R. 2015. pheatmap: Pretty Heatmaps. R package version 1.0.8. https://cran.r-project.org/package=pheatmap.

Kozich JJ, Westcott SL, Baxter NT, Highlander SK, and Schloss PD. 2013. Development of a dual-index sequencing strategy and curation pipeline for analyzing amplicon 
504 Latif H, Li HJ, Charusanti P, Palsson BO, and Aziz RK. 2014. A gapless, unambiguous genome sequence of the enterohemorrhagic Escherichia coli O157:H7 strain EDL933. Genome Announc 2:e00821-00814. 10.1128/genomeA.00821-14

Li B, and Chen JQ. 2012. Real-time PCR methodology for selective detection of viable Escherichia coli $\mathrm{O} 157: \mathrm{H} 7$ cells by targeting Z3276 as a genetic marker. Appl Environ Microbiol 78:5297-5304. 10.1128/aem.00794-12

Li Z, Xu J, Tang C, Wu J, Muhammad A, and Wang H. 2006. Application of 16S rDNA-PCR amplification and DGGE fingerprinting for detection of shift in microbial community diversity in $\mathrm{Cu}-, \mathrm{Zn}-$, and Cd-contaminated paddy soils. Chemosphere 62:1374-1380. 10.1016/j.chemosphere.2005.07.050

Lou J, Gu H, Wang H, An Q, and Xu J. 2016. Complete genome sequence of Massilia sp. WG5, an efficient phenanthrene-degrading bacterium from soil. $J$ Biotechnol

Ma B, Wang H, Dsouza M, Lou J, He Y, Dai Z, Brookes PC, Xu J, and Gilbert JA. 2016. Geographic patterns of co-occurrence network topological features for soil microbiota at continental scale in eastern China. ISME J 10:1891-1901. 10.1038/ismej.2015.261 


\section{Manuscript to be reviewed}

523 Philippot L, Bru D, Saby NP, Cuhel J, Arrouays D, Simek M, and Hallin S. 2009. Spatial

524

525

526

527

528

529

530

531

532

533

534

535

536

537

538

539

540

541

patterns of bacterial taxa in nature reflect ecological traits of deep branches of the $16 \mathrm{~S}$ rRNA bacterial tree. Environ Microbiol 11:3096-3104. 10.1111/j.1462-2920.2009.02014.x

Polka J, Rebecchi A, Pisacane V, Morelli L, and Puglisi E. 2015. Bacterial diversity in typical Italian salami at different ripening stages as revealed by high-throughput sequencing of 16S rRNA amplicons. Food Microbiol 46:342-356. 10.1016/j.fm.2014.08.023

Prest EI, El-Chakhtoura J, Hammes F, Saikaly PE, van Loosdrecht MC, and Vrouwenvelder JS. 2014. Combining flow cytometry and 16S rRNA gene pyrosequencing: a promising approach for drinking water monitoring and characterization. Water Res 63:179-189. 10.1016/j.watres.2014.06.020

Props R, Kerckhof FM, Rubbens P, De Vrieze J, Hernandez Sanabria E, Waegeman W, Monsieurs P, Hammes F, and Boon N. 2017. Absolute quantification of microbial taxon abundances. Isme j 11:584-587. 10.1038/ismej.2016.117

Quast C, Pruesse E, Yilmaz P, Gerken J, Schweer T, Yarza P, Peplies J, and Glockner FO. 2013. The SILVA ribosomal RNA gene database project: improved data processing and web-based tools. Nucleic Acids Res 41:D590-596. 10.1093/nar/gks1219

RCore T. 2013. R: A language and environment for statistical computing. R Foundation for Statistical Computing, Vienna, Austria. URL http://www.r-project.org/. 


\section{Manuscript to be reviewed}

542 Reddy BV, Kallifidas D, Kim JH, Charlop-Powers Z, Feng Z, and Brady SF. 2012. Natural

543

544

545

546

547

548

550

551

552

553

554

555

556

557

558

559

560 product biosynthetic gene diversity in geographically distinct soil microbiomes. Appl Environ Microbiol 78:3744-3752. 10.1128/aem.00102-12

Rouwane A, Rabiet M, Bourven I, Grybos M, Mallet L, and Guibaud G. 2016. Role of microbial reducing activity in antimony and arsenic release from an unpolluted wetland soil: a lab scale study using sodium azide as a microbial inhibiting agent. Environmental Chemistry 13:945-954. 10.1071/en16029

Singer E, Andreopoulos B, Bowers RM, Lee J, Deshpande S, Chiniquy J, Ciobanu D, Klenk HP, Zane M, Daum C, Clum A, Cheng JF, Copeland A, and Woyke T. 2016. Next generation sequencing data of a defined microbial mock community. Sci Data 3:160081. 10.1038/sdata.2016.81

Smets W, Leff JW, Bradford MA, McCulley RL, Lebeer S, and Fierer N. 2016. A method for simultaneous measurement of soil bacterial abundances and community composition via $16 \mathrm{~S}$ rRNA gene sequencing. Soil Biology \& Biochemistry 96:145-151. 10.1016/j.soilbio.2016.02.003

Stokell JR, Hamp TJ, and Steck TR. 2016. Examining changes in bacterial abundance in complex communities using next-generation sequencing is enhanced with quantitative PCR. Antonie Van Leeuwenhoek International Journal of General and Molecular Microbiology 109:1161-1166. 10.1007/s10482-016-0707-4 


\section{Manuscript to be reviewed}

561 Tourlousse DM, Yoshiike S, Ohashi A, Matsukura S, Noda N, and Sekiguchi Y. 2017. 562 Synthetic spike-in standards for high-throughput 16S rRNA gene amplicon $563 \quad$ sequencing. Nucleic acids research 45:14. 10.1093/nar/gkw984

564 Vance E, Brookes P, and Jenkinson D. 1987. An extraction method for measuring soil 565 microbial biomass C. Soil Biol Biochem 19:703-707.

566 Wang H, Ibekwe AM, Ma J, Wu L, Lou J, Wu Z, Liu R, Xu J, and Yates SR. 2014. A glimpse 567 of Escherichia coli O157:H7 survival in soils from eastern China. Science of the Total Environment 476:49-56. 10.1016/j.scitotenv.2014.01.004

569 Wang H, Lou J, Gu H, Luo X, Yang L, Wu L, Liu Y, Wu J, and Xu J. 2016. Efficient biodegradation of phenanthrene by a novel strain Massilia sp. WF1 isolated from a PAH-contaminated soil. Environ Sci Pollut Res Int 23:13378-13388. $10.1007 / \mathrm{s} 11356-016-6515-6$

573 Wang Q, Garrity GM, Tiedje JM, and Cole JR. 2007. Naive Bayesian classifier for rapid assignment of rRNA sequences into the new bacterial taxonomy. Appl Environ Microbiol 73:5261-5267. 10.1128/aem.00062-07

576 Wei S, and Pan S. 2010. Phytoremediation for soils contaminated by phenanthrene and 577 578 pyrene with multiple plant species. $J$ Soils Sediments 10:886-894.

579 Whitman WB, Coleman DC, and Wiebe WJ. 1998. Prokaryotes: the unseen majority. Proc Natl Acad Sci U S A 95:6578-6583. 
581 Youssef N, Sheik CS, Krumholz LR, Najar FZ, Roe BA, and Elshahed MS. 2009.

582 Comparison of species richness estimates obtained using nearly complete fragments

583 and simulated pyrosequencing-generated fragments in $16 \mathrm{~S}$ rRNA gene-based

584 environmental surveys. Appl Environ Microbiol 75:5227-5236.

$585 \quad 10.1128 /$ aem.00592-09

586 Zhang Z, Qu Y, Li S, Feng K, Wang S, Cai W, Liang Y, Li H, Xu M, Yin H, and Deng Y.

587 2017. Soil bacterial quantification approaches coupling with relative abundances

588 reflecting the changes of taxa. Sci Rep 7:4837. 10.1038/s41598-017-05260-w

589 


\section{Table $\mathbf{1}$ (on next page)}

Detection and calculation of the added internal reference strain EDL933 (copies ( $\mathrm{g}$ dry wt soil) ${ }^{-1}$ ) in soil by qPCR (fliC gene and $7 \times$ fliC gene ) and iHAAQ method (Esch-V3 and Esch-V4).

Treatments E9 to E4 are corresponding to with 6 different concentrations of $10^{9}$ to $10^{4} \mathrm{CFU}$ (g dry wt soil $)^{-1}$. Different letters indicate significant difference $(p<0.05)$ among $7 \times$ flic gene, Esch-V3 and Esch-V4 of each treatment detected by ANOVA test. 


\section{$1 \quad$ Table 1}

\begin{tabular}{lcccc}
\hline Treatment & fliC & $7 \times f l i C$ & Esch-V3 & Esch-V4 \\
\hline E9 & $4.79 \times 10^{9} \pm 1.30 \times 10^{9}$ & $3.35 \times 10^{10} \pm 9.11 \times 10^{8} \mathrm{a}$ & $4.67 \times 10^{10} \pm 9.07 \times 10^{8} \mathrm{a}$ & $4.82 \times 10^{10} \pm 1.09 \times 10^{9} \mathrm{a}$ \\
& & & & \\
E8 & $5.96 \times 10^{8} \pm 1.20 \times 10^{7}$ & $4.17 \times 10^{9} \pm 8.38 \times 10^{7} \mathrm{ab}$ & $3.59 \times 10^{9} \pm 2.20 \times 10^{8} \mathrm{~b}$ & $4.37 \times 10^{9} \pm 3.53 \times 10^{8} \mathrm{a}$ \\
& & & & \\
E7 & $5.28 \times 10^{7} \pm 1.40 \times 10^{6}$ & $3.70 \times 10^{8} \pm 9.80 \times 10^{6} \mathrm{a}$ & $2.94 \times 10^{8} \pm 1.17 \times 10^{7} \mathrm{a}$ & $3.39 \times 10^{8} \pm 1.13 \times 10^{7} \mathrm{a}$ \\
& & & & \\
E6 & $5.70 \times 10^{6} \pm 4.62 \times 10^{5}$ & $3.99 \times 10^{7} \pm 3.23 \times 10^{6} \mathrm{a}$ & $2.82 \times 10^{7} \pm 3.86 \times 10^{6} \mathrm{~b}$ & $4.08 \times 10^{7} \pm 2.52 \times 10^{6} \mathrm{a}$ \\
& & & & \\
E5 & $5.65 \times 10^{5} \pm 5.19 \times 10^{4}$ & $3.95 \times 10^{6} \pm 3.63 \times 10^{5} \mathrm{ab}$ & $3.48 \times 10^{6} \pm 2.83 \times 10^{4} \mathrm{~b}$ & $6.47 \times 10^{6} \pm 2.07 \times 10^{5} \mathrm{a}$ \\
& & & & \\
E4 & $8.11 \times 10^{4} \pm 3.15 \times 10^{3}$ & $5.68 \times 10^{5} \pm 2.21 \times 10^{4} \mathrm{c}$ & $1.47 \times 10^{6} \pm 7.66 \times 10^{4} \mathrm{~b}$ & $3.14 \times 10^{6} \pm 1.25 \times 10^{5} \mathrm{a}$ \\
\hline
\end{tabular}




\section{Figure 1}

A schematic workflow of the iHAAQ method and its validation procedure.

For method validation, the internal reference strain (IRS) was introduced into soil before DNA extraction and measured by iHAAQ and qPCR methods. These two results were combined and analyzed by liner regression to validate the iHAAQ method.

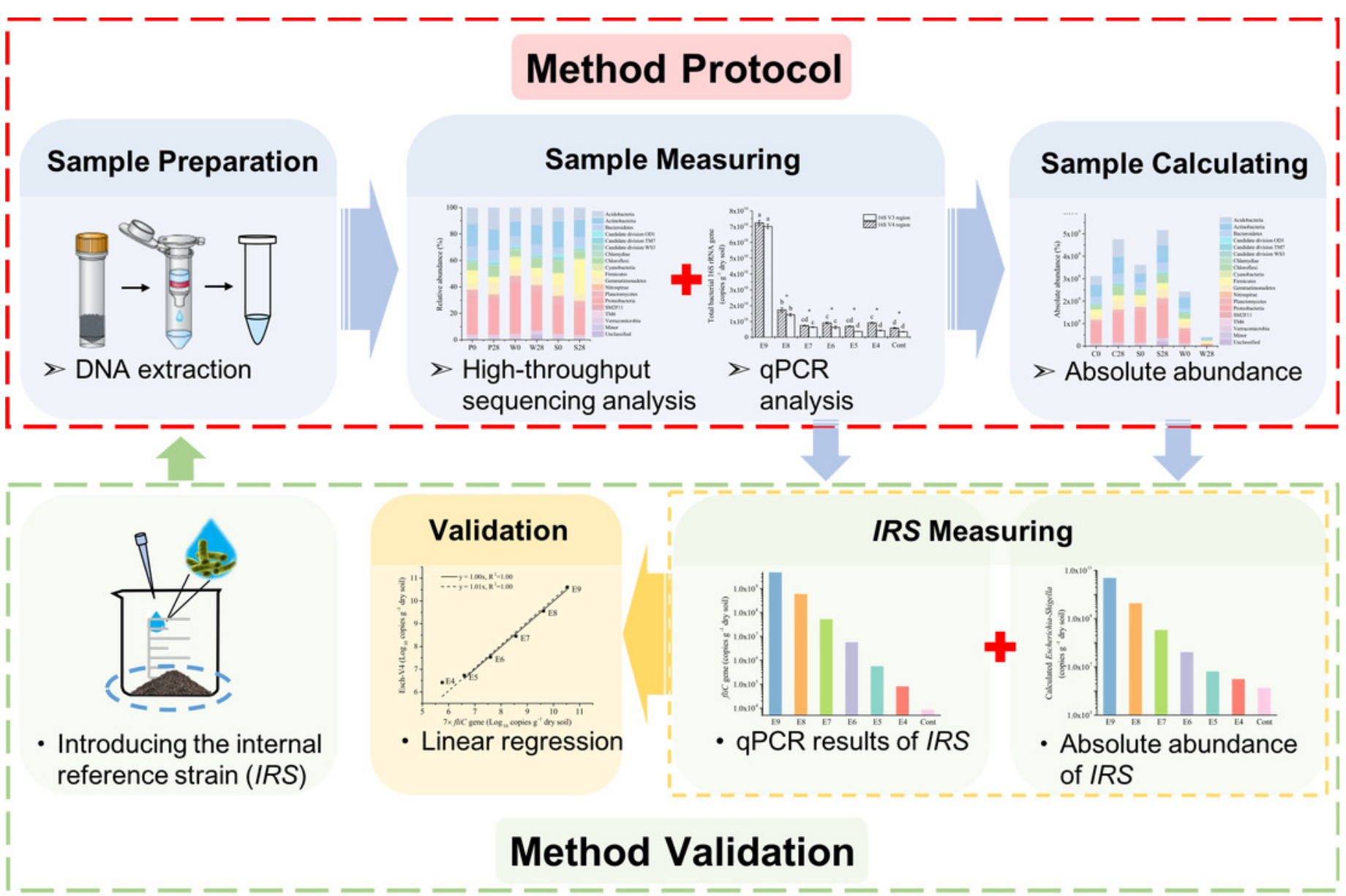


Figure 2

Relative abundances of Escherichia-Shigella genus in the different treatments.

The added internal standard strain EDL933 is classified as Escherichia-Shigella genus in the SILVA database. Treatments E9 to E4 are the same as described in Table 1, and Cont is the original control soil.

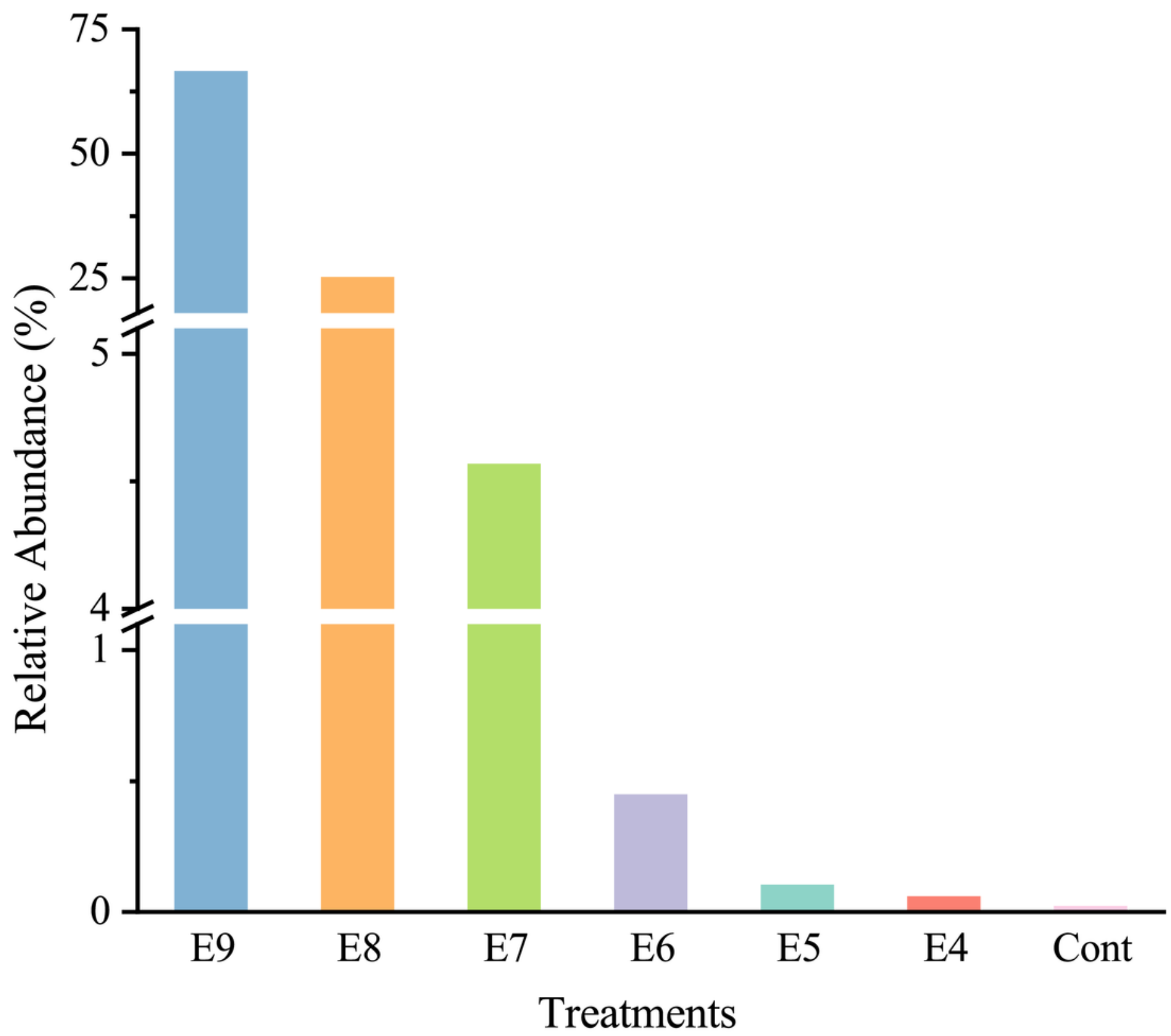


Figure 3

Linear regressions for the quantities of added internal standard strain EDL933 from qPCR and iHAAQ methods in the different treatments.

The $7 \times$ fliC gene copies of added internal standard strain EDL933 detected by qPCR. The

Esch-V3 (A) and Esch-V4 (B) represent Escherichia-Shigella copies calculated by iHAAQ method with its relative abundance multiplying by the total bacterial 16S rRNA gene copies in V3 and V4 variable regions, respectively. All intercepts were fixed to the origin point (0). Treatments E9 to E4 are the same as described in Table 1. The solid and dash lines represent the linear models without and with Treatment E4, respectively.
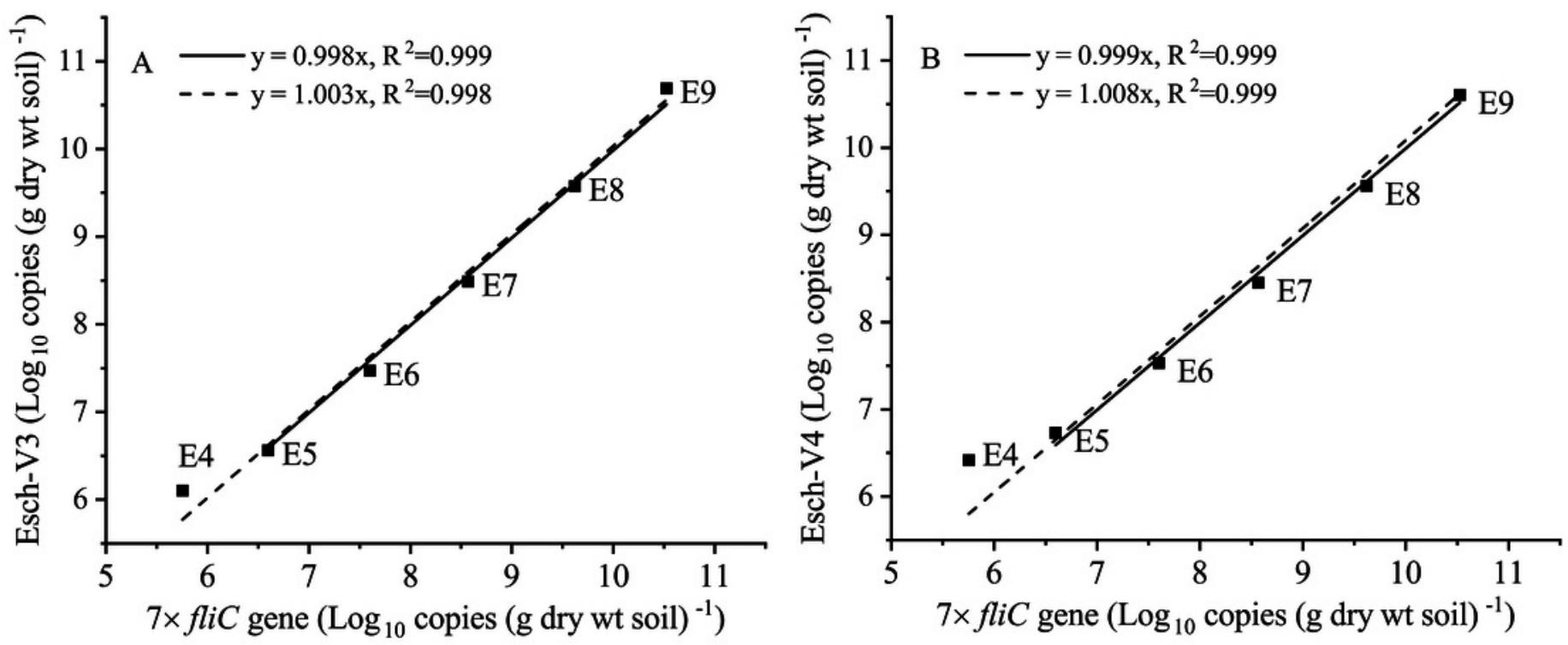


\section{Figure 4}

Absolute abundances of the major phyla in different treatments.

All classified phyla with a relative abundance of $<0.1 \%$ in a sample were combined and reported as Minor. Treatments E9 to E4 are the same as in Table 1, and the Cont is the original control soil. No shade and shadow histograms represent the phyla number quantified by the V3 and V4 regions of 16S rRNA gene, respectively.

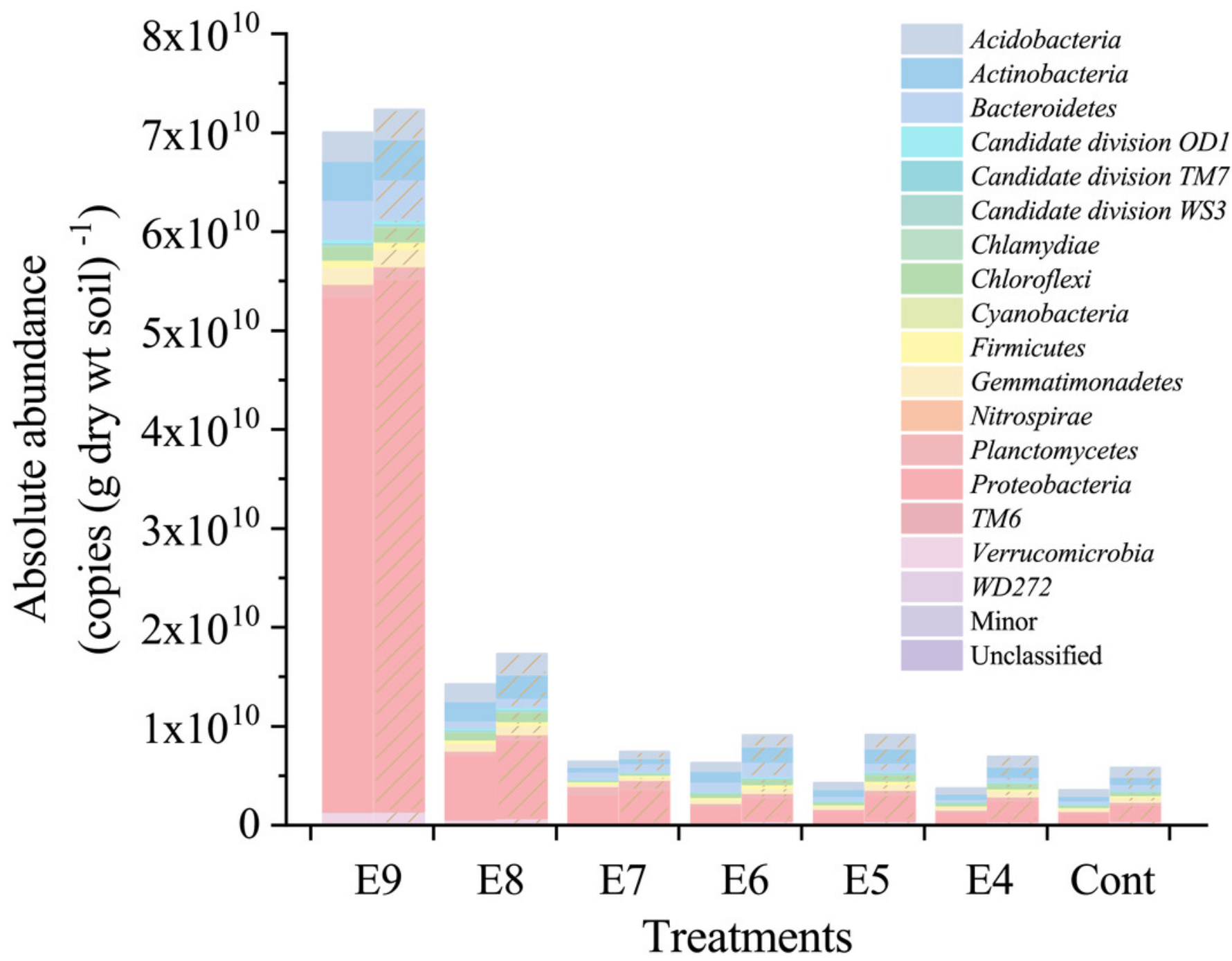




\section{Figure 5}

Absolute abundances of the major phyla determined by the iHAAQ method in different soil samples.

All classified phyla with a relative abundance of $<0.1 \%$ in a sample were combined and reported as Minor. P, S, and W represent the treatments of soil added with PHE (100 $\mu \mathrm{g}$ (g dry wt soil)-1 $), \operatorname{NaN}_{3}(0.1 \%, w / w)$, and PHE (100 $\mu \mathrm{g}$ (g dry wt soil) $\left.)^{-1}\right)$ and strain WG5 (approximately $1.00 \times 10^{7} \mathrm{CFU}(\mathrm{g} \text { dry wt soil) })^{-1}$ ), respectively. 0 and 28 represent sampling at 0 and 28 days of incubation. No shade and shadow histograms represent the phyla number quantified by the V3 and V4 regions of 16S rRNA gene, respectively.

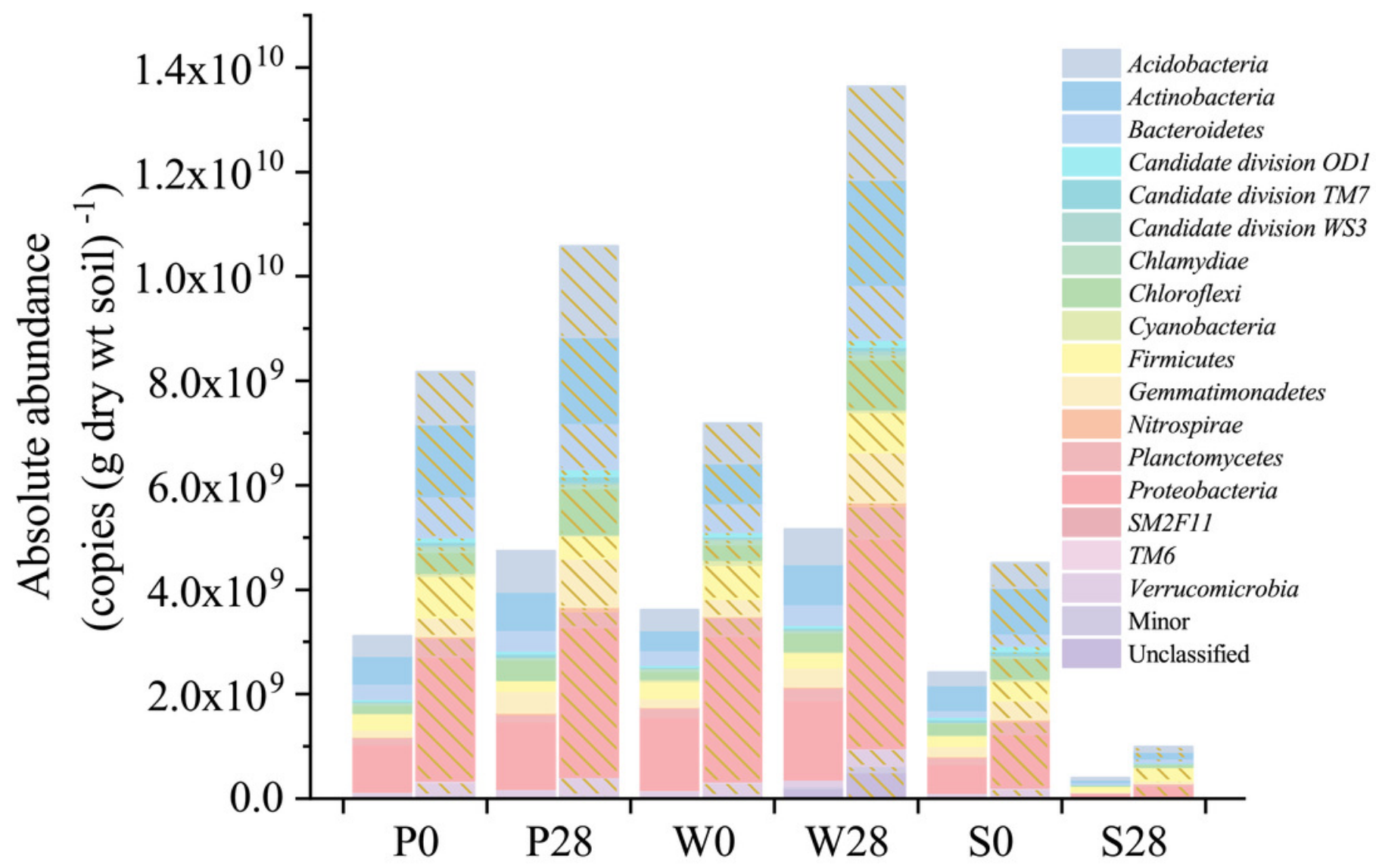




\section{Figure 6}

Heatmaps showing the relative abundances $(A)$ and absolute abundances $(B)$ determined by the iHAAQ method of the major phyla quantified by the $\mathrm{V} 4$ region of $16 \mathrm{~S}$ rRNA gene.

All classified phyla with a relative abundance of $<0.1 \%$ in a sample were combined and reported as Minor. P0, P28, S0, S28, W0 and W28 are the same as in Fig. 5. The color codes indicate the relative $(A)$ or absolute $(B)$ abundances, ranging from blue (low abundance) to red (high abundance).
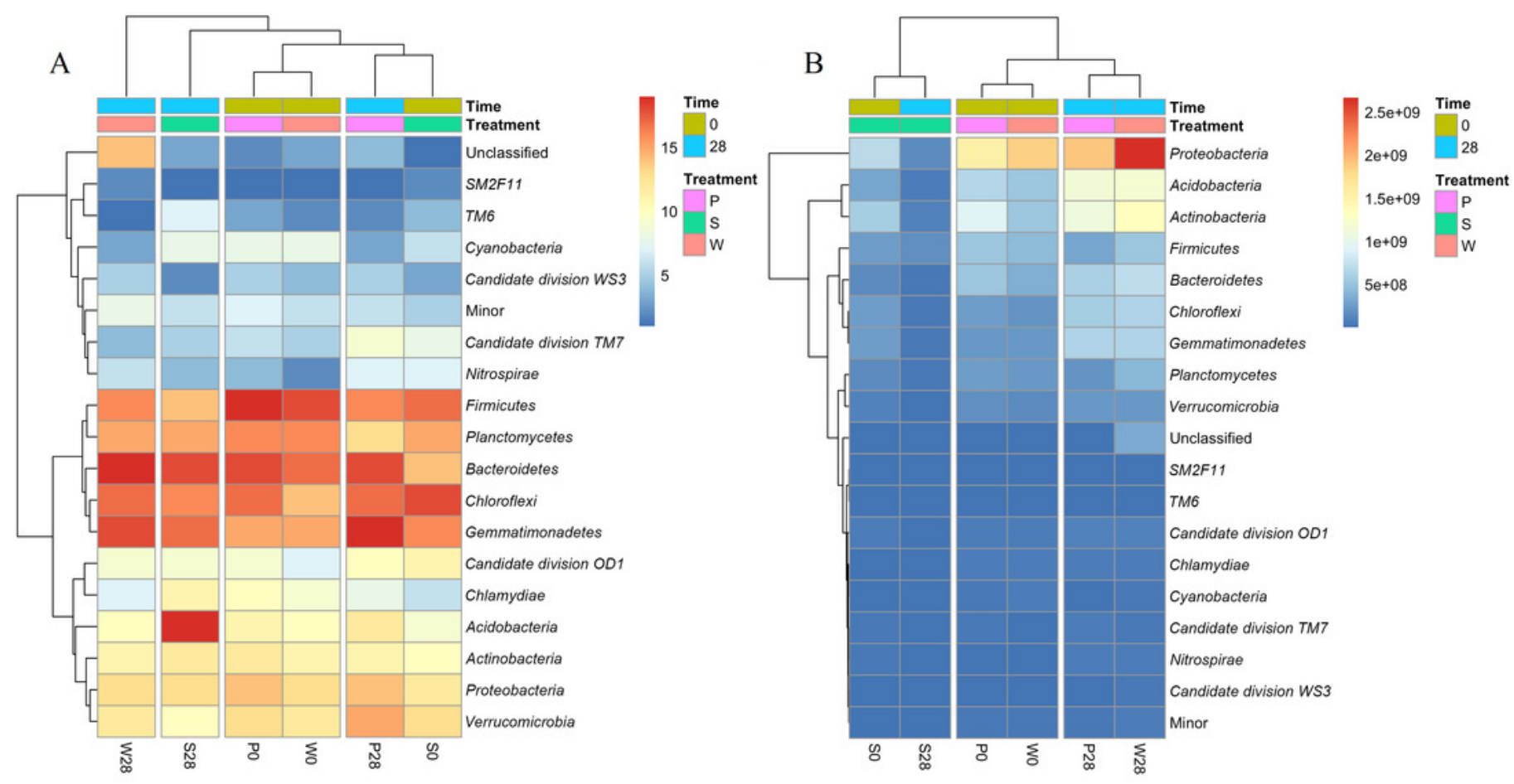
Figure 7

The representative genera of Treatments $\mathrm{P}, \mathrm{W}$, and $\mathrm{S}$.

P0, P28, S0, S28, W0 and W28 are the same as in Fig. 5.
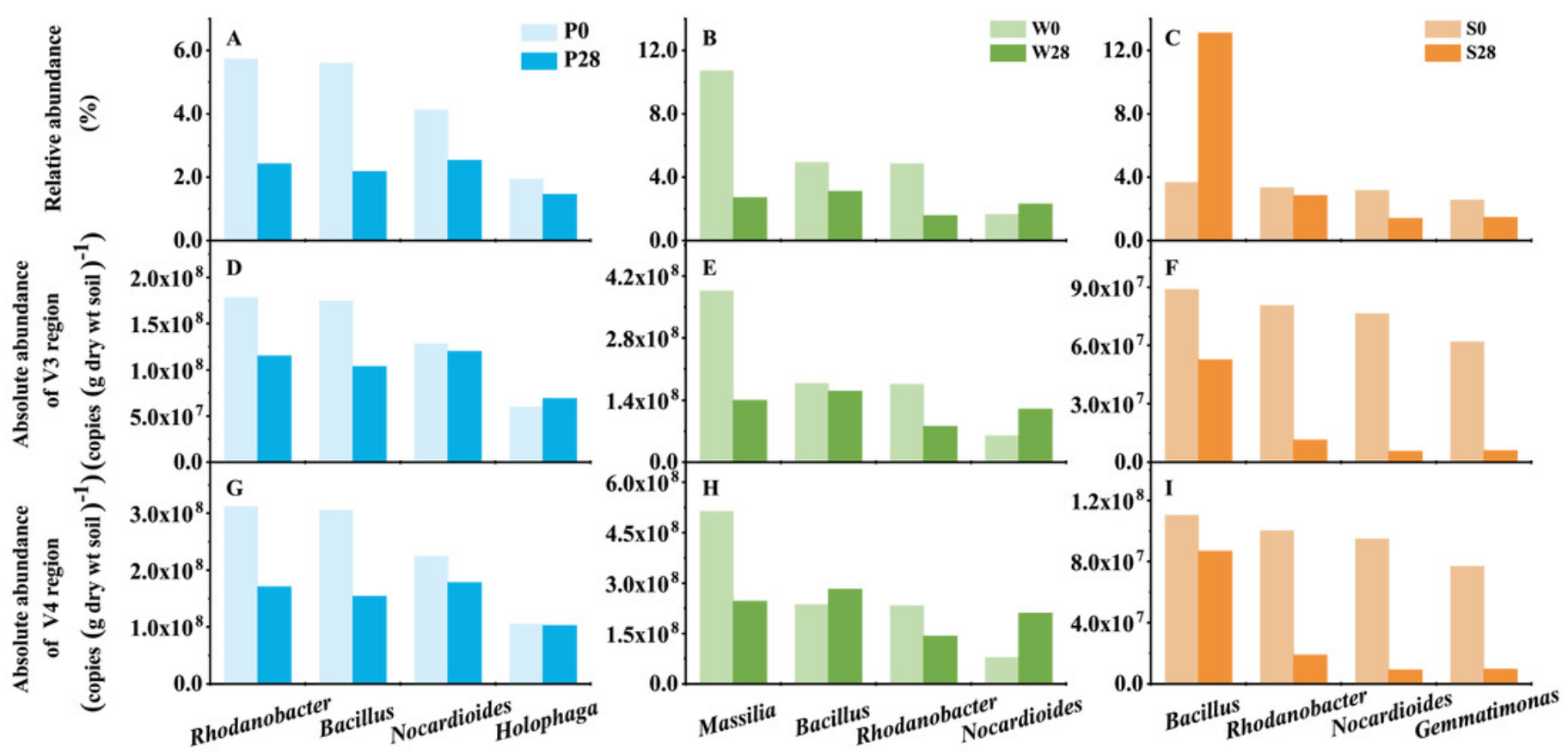